Review began 10/05/2021 Review ended 10/12/2021 Published 10/14/2021

() Copyright 2021

Al Amri et al. This is an open access article distributed under the terms of the Creative Commons Attribution License CC-BY 4.0. which permits unrestricted use, distribution, and reproduction in any medium, provided the original author and source are credited.

\section{Knowledge, Attitude and Practice Regardling Risk of Diabetic Foot Among Diabetic Patients in Aseer Region, Saudi Arabia}

Ali M. Al Amri ${ }^{1}$, Ibarhim M. Shahrani ${ }^{2}$, Yazan A. Almaker ${ }^{2}$, Daher M. Alshehri ${ }^{2}$, Mohammed A. Argabi ${ }^{2}$, Fouad A. Alghamidi ${ }^{2}$, Yahya Z. Alqahtani ${ }^{3}$

1. Family Medicine \& Diabetes, Asir Central Hospital, Abha, SAU 2 2. College of Medicine, King Khalid University, Abha, SAU 3. Surgery, Asir Central Hospital, Abha, SAU

Corresponding author: Ibarhim M. Shahrani, dr.ibraheem.muria@gmail.com

\section{Abstract}

\section{Background}

Diabetic foot care is vital as it is preventable complication but dangerous even a small trauma can end with serious consequences. Diabetes may cause nerve damage that affects feet sensation. Diabetes may also reduce blood flow to the feet, making it harder to heal an injury or resist infection. Because of these problems, patients may lose notice of early foot abnormalities. Diabetic patients' awareness regarding how to care for their feet plays a significant role in preventing these complications.

\section{Methods}

A correlation cross-sectional study was conducted targeting all diabetic patients aging 20 years or more. Online questionnaire was used for data collection. Questionnaire was uploaded online using social media platforms by the researchers and their relatives and friends. The questionnaire included patient personal data, patients' knowledge regarding diabetic foot, attitude and practice regarding the risk of diabetic foot among diabetic patients.

\section{Results}

A total of 1,000 diabetic patients fulfilling the inclusion criteria completed the study questionnaire. Exact of $77.5 \%$ of the patients know that Diabetics can get gangrene in the foot, $74.9 \%$ know diabetics can develop ulcers in the foot, $66.7 \%$ reported that Diabetes can reduce blood flow to the feet of diabetic patients, $66.6 \%$ agreed that diabetic patients can suffer from a lack of sensation in the feet. Exact of $84.5 \%$ of the study participants agreed that Diabetics should check for any wounds on their feet daily, $78.7 \%$ agreed that Diabetics should visit a doctor when there is any infection or wound in the feet, $76.6 \%$ think that diabetic patients should wear specialized shoes to avoid diabetic foot according to the doctor's instructions. A total of 822 (82.2\%) of the study patients wash their feet daily, and 295 (29.5\%) usually wear cotton socks regularly and 39.6\% sometimes wear the stock. Only 192 (19.2\%) regularly walk barefoot and 41.7\% sometimes do.

\section{Conclusion}

In conclusion, the current study results showed that nearly two out of each three diabetic patients were knowledgeable for diabetic foot and its care. High knowledge was associated with young age, high education and having family member with diabetes mellitus (DM). Also, patients had a good attitude towards diabetic foot care and the effect of diabetes on foot health with to some level accepted practice except for some issues.

Categories: Endocrinology/Diabetes/Metabolism, Family/General Practice

Keywords: foot ulcers, awareness, attitude, practice, knowledge, care, diabetic foot, complications, diabetes mellitus

\section{Introduction}

Diabetes mellitus (DM) is a worldwide public health problem. with chronic progressive metabolic disorder featured by hyperglycaemia, caused by either deficiency or resistance to the insulin hormone [1,2]. A diabetic foot is one of the diabetes complications caused due from peripheral arterial disease (PAD) with sensory neuropathy at diabetic patients' feet [3,4]. Diabetic foot is a long-lasting complication of diabetes with a high burden that affects diabetic patients' quality of life [5-7]. Presence of several characteristic diabetic foot pathologies such as infection, diabetic foot ulcer and neuropathic osteoarthropathy is called diabetic foot syndrome [8].

There are many risk factors of the diabetic foot include old age, duration of diabetes, and hypertension. 
Peripheral neuropathy associated with sensory loss and peripheral vascular disease-resulting ischemia are the leading risk factors causing foot ulcer and eventually foot amputation [9-11]. And diabetic foot ulcers are frequent and most disturbing preventable complications of patients with long-term uncontrolled diabetes mellitus [12]. Diabetic foot ulcer-associated morbidity and early mortality because of chronic complications of foot was recorded. [11,12]. The most reported sites of these ulcers are the areas of the foot that encounters frequent trauma and pressure sensations [13]. Most of the diabetic foot complications can be prohibited with alert foot care. It takes effort and time to build up good foot care habits, but self-care is essential $[14,15]$.

Diabetic patients' awareness regarding how to care for their feet plays a significant role in preventing these complications with decreased social, medical, and economic burden of its consequences including foot ulcers and amputation. The current study aimed to assess the knowledge, attitudes, practices and risk factors influencing diabetic foot ulcers among diabetes patients in Aseer region, Southern of Saudi Arabia.

\section{Materials And Methods}

\section{Methodology}

A correlation cross-sectional study was conducted targeting all diabetic patients aging 20 years or more. Patients less than 20 years, Patient who is already having diabetic foot, amputated foot, or foot ulcers, and those who did not fill the study questionnaire were excluded. After having ethical approval, and due to the current environment due to COVID-19 pandemic, online questionnaire was used for data collection. All accessible adults in the general population were invited to fill the uploaded questionnaire consecutively till achieving the required sample size. The questionnaire was developed by researchers after intensive literature reviews and expert's consultation. Study questionnaire validity was assessed by a panel of three experts in diabetology with applying all confirmed modifications. Also, reliability and clarity were assessed using pilot of 30 diabetic patients who were excluded from the main study with $\alpha$-Cronbach's of 0.74 . The questionnaire included patient personal data, patients' knowledge regarding diabetic foot, attitude and practice regarding the risk of diabetic foot among diabetic patients. Questionnaire was uploaded online using social media platforms by the researchers and their relatives and friends.

\section{Data analysis}

After data were extracted, it was revised, coded, and fed to statistical software IBM SPSS version 22(SPSS, Inc. Chicago, IL). All statistical analysis was done using two-tailed tests. p-value less than 0.05 was statistically significant. For knowledge items, each correct answer was scored one point and the total summation of the discrete scores of the different items was calculated. A patient with a score less than $60 \%$ of the total score was considered to have poor awareness while good awareness was considered if he had a score of $60 \%$ of the total or more. Descriptive analysis based on frequency and percent distribution was done for all variables including participants' age, gender, education level, family history of diabetes. Also, participants' knowledge items regarding diabetic foot, attitude towards diabetic foot care, and patients practice towards their foot were displayed. Crosstabulation was used to assess the distribution of knowledge level according to participants' personal data and the distribution of patients practice according to their knowledge level. Relations were tested using Pearson chi-square test.

The study was approved by Regional Committee for Research Ethics, Directorate Health Affairs-Aseer Region with a study number of (REC-02-09-202). After the institutional review board (IRB) approval, the data was collected only by authorized members.

\section{Results}

A total of 1,000 diabetic patients fulfilling the inclusion criteria completed the study questionnaire. Patients ages ranged from 20 to 59 years old with a mean age of $42.6 \pm 11.8$ years old. Exact of 670 (67\%) of the patients were males and 658 (65.8\%) were married. As for educational level, 566 (56.6\%) were university graduated and 238 (23.8\%) had secondary level of education. Exact of 678 (67.8\%) patients had family history of diabetes (Table 1 ). 


\section{Cureus}

Personal data

Age in years

$20-40$

$41-50$

$>50$

Gender

Male

Female

Marital status

Single

Married

Educational level

Below secondary

Secondary

University/above

Does anyone in your family have diabetes?

Yes

No

TABLE 1: . Personal data of diabetic patients, Aseer region, Saudi Arabia.
$\%$

$39.1 \%$

$34.8 \%$

$26.1 \%$

670

$67.0 \%$

330

$33.0 \%$

342

$34.2 \%$

658

$65.8 \%$

196

$19.6 \%$

238

$23.8 \%$

566

$56.6 \%$

678

$67.8 \%$

322

$32.2 \%$

Exact of $77.5 \%$ of the patients know that diabetics can get gangrene in the foot, $74.9 \%$ know diabetics can develop ulcers in the foot, $66.7 \%$ reported that diabetes can reduce blood flow to the feet of diabetic patients, $66.6 \%$ agreed that diabetic patients can suffer from a lack of sensation in the feet, and $51.4 \%$ know smoking can reduce blood flow to the feet (Table 2).

\begin{tabular}{|c|c|c|c|c|c|c|}
\hline \multirow{2}{*}{ Knowledge item } & \multicolumn{2}{|l|}{ Yes } & \multicolumn{2}{|l|}{ No } & \multicolumn{2}{|c|}{ Dont know } \\
\hline & No & $\%$ & No & $\%$ & No & $\%$ \\
\hline Diabetes can reduce blood flow to the feet of diabetic patients? & 667 & $66.7 \%$ & 80 & $8.0 \%$ & 253 & $25.3 \%$ \\
\hline Diabetic patient can suffer from a lack of sensation in the feet? & 666 & $66.6 \%$ & 113 & $11.3 \%$ & 221 & $22.1 \%$ \\
\hline Diabetics can develop ulcers in the foot? & 749 & $74.9 \%$ & 98 & $9.8 \%$ & 153 & $15.3 \%$ \\
\hline Diabetics can get gangrene in the foot? & 775 & $77.5 \%$ & 95 & $9.5 \%$ & 130 & $13.0 \%$ \\
\hline Smoking can reduce blood flow to the feet? & 514 & $51.4 \%$ & 132 & $13.2 \%$ & 354 & $35.4 \%$ \\
\hline
\end{tabular}

TABLE 2: Distribution of knowledge regarding diabetic foot care among diabetic patients, Aseer region, Saudi Arabia.

Exact of 674 (67.4\%) patients had a good knowledge level regarding diabetic foot, while 326 (32.6\%) had poor knowledge level (Figure 1). 


\section{Cureus}

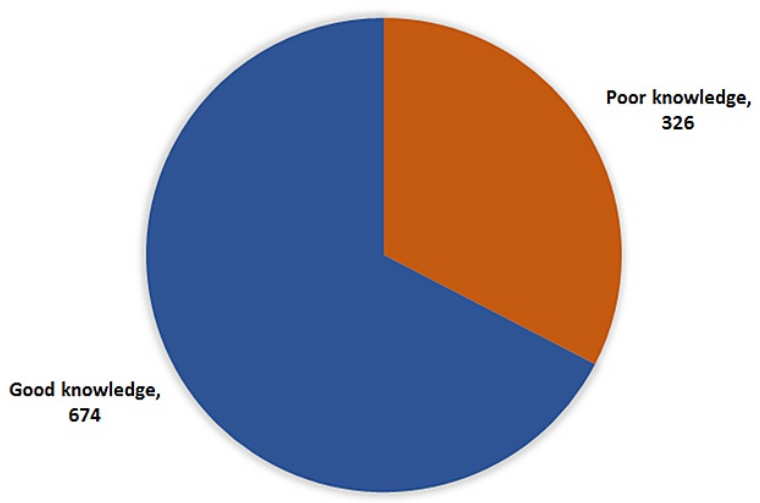

\section{FIGURE 1: Overall knowledge regarding diabetic foot among diabetic}

patients, Aseer region, Saudi Arabia.

Exact of $84.5 \%$ of the study participants agreed that diabetics should check for any wounds on their feet daily, $78.7 \%$ agreed that diabetics should visit a doctor when there is any infection or wound in the feet, $76.6 \%$ think that diabetic patients should wear specialized shoes to avoid diabetic foot according to the doctor's instructions. Only $20.9 \%$ agreed that diabetics should not make periodic visits to the diabetes clinic for the purpose of examination and $16.5 \%$ believe that I can treat myself if I have diabetes without consulting a doctor (Table 3).

\begin{tabular}{|c|c|c|c|c|c|c|}
\hline \multirow{2}{*}{ Attitude items } & \multicolumn{2}{|c|}{ Disagree } & \multicolumn{2}{|c|}{ Agree } & \multicolumn{2}{|c|}{ Unsure } \\
\hline & No & $\%$ & No & $\%$ & No & $\%$ \\
\hline Diabetics should check for any wounds on their feet daily & 72 & $7.2 \%$ & 845 & $84.5 \%$ & 83 & $8.3 \%$ \\
\hline Diabetics should visit a doctor when there is any infection or wound in the feet & 93 & $9.3 \%$ & 787 & $78.7 \%$ & 120 & $12.0 \%$ \\
\hline $\begin{array}{l}\text { Dlabetic patients snould wear speclallzed snoes to avold dabetic toot accoraing to the doctor's } \\
\text { instructions }\end{array}$ & 110 & $11.0 \%$ & 766 & $76.6 \%$ & 124 & $12.4 \%$ \\
\hline Diabetics should not make periodic visits to the diabetes clinic for the purpose of examination & 693 & $69.3 \%$ & 209 & $20.9 \%$ & 98 & $9.8 \%$ \\
\hline I believe that I can trea & 660 & $66.0 \%$ & 165 & $16.5 \%$ & 175 & 17.5 \\
\hline
\end{tabular}

TABLE 3: Distribution of attitude towards diabetic foot care among diabetic patients, Aseer region, Saudi Arabia.

A total of $822(82.2 \%)$ of the study patients wash their feet daily, and 295 (29.5\%) usually wear cotton socks regularly and 39.6\% sometimes wear the stock. Only 192 (19.2\%) regularly walk barefoot and 41.7\% sometimes do. Changing shoes when damaged only is reported among $47 \%$ of the patients while $35.9 \%$ change the shoes more than once a year. Checking foot for any deformity was done monthly among $8.3 \%$ of the patients while $11.8 \%$ do it every six months, $11.3 \%$ do every year and $68.6 \%$ seek care when sick only. Exact of $70.4 \%$ of the patients reported that they Consult a physician when found any deformity (wound/ulcer) in their feet (Table 4). 


\section{Cureus}

Practice items

Do you wash your feet daily?

Yes

Sometimes

Do you wear cotton socks regularly?

Yes

Sometimes

Do you always walk barefoot?

Yes

Sometimes

How often do you change your shoes?

Once per year

More than once pr year

When the shoe is damaged

How often do you go to check your feet?

Monthly

Every 6 months

Every year

What do you do if you find deformities (wounds/ulcers) on your feet?

TABLE 4: Distribution of diabetic patients practice regarding diabetic foot care, Aseer region, Saudi Arabia.

Good knowledge was detected among $71.6 \%$ of young age patients compared to $59.4 \%$ of old age group with recorded statistical significance $(\mathrm{p}=0.004)$. Also, $76.3 \%$ of the diabetic patients were university graduated versus $44.4 \%$ of those with below secondary education ( $p=0.001$ ). Exact of $69.2 \%$ of patients with a family history of diabetes had good knowledge regarding diabetic foot care in comparison to $63.7 \%$ of those without $(\mathrm{p}=0.049)$ (Table 5). 


\section{Cureus}

\begin{tabular}{|c|c|c|c|c|c|}
\hline \multirow{3}{*}{ Personal data } & \multicolumn{4}{|c|}{ Knowledge level } & \multirow{3}{*}{ p-value } \\
\hline & \multicolumn{2}{|c|}{ Poor } & \multicolumn{2}{|c|}{ Good } & \\
\hline & No & $\%$ & No & $\%$ & \\
\hline \multicolumn{6}{|l|}{ Age in years } \\
\hline $20-40$ & 111 & $28.4 \%$ & 280 & $71.6 \%$ & \multirow{3}{*}{$0.004^{*}$} \\
\hline $41-50$ & 109 & $31.3 \%$ & 239 & $68.7 \%$ & \\
\hline$>50$ & 106 & $40.6 \%$ & 155 & $59.4 \%$ & \\
\hline \multicolumn{5}{|l|}{ Gender } & \multirow{3}{*}{0.177} \\
\hline Male & 209 & $31.2 \%$ & 461 & $68.8 \%$ & \\
\hline Female & 117 & $35.5 \%$ & 213 & $64.5 \%$ & \\
\hline \multicolumn{5}{|l|}{ Marital status } & \multirow{3}{*}{0.102} \\
\hline Single & 123 & $36.0 \%$ & 219 & $64.0 \%$ & \\
\hline Married & 203 & $30.9 \%$ & 455 & $69.1 \%$ & \\
\hline \multicolumn{5}{|l|}{ Educational level } & \multirow{4}{*}{$0.001^{*}$} \\
\hline Below secondary & 109 & $55.6 \%$ & 87 & $44.4 \%$ & \\
\hline Secondary & 83 & $34.9 \%$ & 155 & $65.1 \%$ & \\
\hline University/above & 134 & $23.7 \%$ & 432 & $76.3 \%$ & \\
\hline \multicolumn{5}{|c|}{ Does anyone in your family have diabetes? } & \multirow{3}{*}{$0.049^{*}$} \\
\hline Yes & 209 & $30.8 \%$ & 469 & $69.2 \%$ & \\
\hline No & 117 & $36.3 \%$ & 205 & $63.7 \%$ & \\
\hline
\end{tabular}

TABLE 5: Distribution of diabetic patients' overall knowledge regarding diabetic foot by their personal data.

P: Pearson $X^{2}$ test. ${ }^{*} p<0.05$ (significant).

Exact of $88.6 \%$ of diabetic patients with good knowledge level was their feet daily compared to $69 \%$ of others with poor knowledge $(\mathrm{p}=0.001)$. Also, $35.3 \%$ of diabetic patients with good knowledge wear cotton socks regularly versus $17.5 \%$ of those with poor knowledge ( 0.001$)$. Exact of $14.5 \%$ of patients with good knowledge change their shoes annually versus $22.4 \%$ of those with poor knowledge $(\mathrm{p}=0.008)$ (Table 6$)$. 


\section{Cureus}

\begin{tabular}{|c|c|c|c|c|c|}
\hline \multirow{3}{*}{ Practice } & \multicolumn{4}{|c|}{ Knowledge level } & \multirow{3}{*}{ p-value } \\
\hline & \multicolumn{2}{|l|}{ Poor } & \multicolumn{2}{|c|}{ Good } & \\
\hline & No & $\%$ & No & $\%$ & \\
\hline Do you wash your feet daily? & & & & & \multirow{4}{*}{$0.001^{*}$} \\
\hline Yes & 225 & $69.0 \%$ & 597 & $88.6 \%$ & \\
\hline Sometimes & 61 & $18.7 \%$ & 50 & $7.4 \%$ & \\
\hline No & 40 & $12.3 \%$ & 27 & $4.0 \%$ & \\
\hline \multicolumn{5}{|c|}{ Do you wear cotton socks regularly? } & \multirow{4}{*}{$0.001^{*}$} \\
\hline Yes & 57 & $17.5 \%$ & 238 & $35.3 \%$ & \\
\hline Sometimes & 158 & $48.5 \%$ & 238 & $35.3 \%$ & \\
\hline No & 111 & $34.0 \%$ & 198 & $29.4 \%$ & \\
\hline \multicolumn{5}{|l|}{ Do you always walk barefoot? } & \multirow{4}{*}{0.379} \\
\hline Yes & 62 & $19.0 \%$ & 130 & $19.3 \%$ & \\
\hline Sometimes & 127 & $39.0 \%$ & 290 & $43.0 \%$ & \\
\hline No & 137 & $42.0 \%$ & 254 & $37.7 \%$ & \\
\hline \multicolumn{5}{|c|}{ How often do you change your shoes? } & \multirow{4}{*}{$0.008^{*}$} \\
\hline Once per year & 73 & $22.4 \%$ & 98 & $14.5 \%$ & \\
\hline More than once pr year & 107 & $32.8 \%$ & 252 & $37.4 \%$ & \\
\hline When the shoe is damaged & 146 & $44.8 \%$ & 324 & $48.1 \%$ & \\
\hline \multicolumn{5}{|c|}{ How often do you go to check your feet? } & \multirow{5}{*}{$0.001^{*}$} \\
\hline Monthly & 32 & $9.8 \%$ & 51 & $7.6 \%$ & \\
\hline Every 6 months & 46 & $14.1 \%$ & 72 & $10.7 \%$ & \\
\hline Every year & 53 & $16.3 \%$ & 60 & $8.9 \%$ & \\
\hline When I am sick & 195 & $59.8 \%$ & 491 & $72.8 \%$ & \\
\hline \multicolumn{5}{|c|}{ What do you do if you find deformities (wounds/ulcers) on your feet? } & \multirow{3}{*}{0.506} \\
\hline Consult a physician & 225 & $69.0 \%$ & 479 & $71.1 \%$ & \\
\hline Treat by yourself & 101 & $31.0 \%$ & 195 & $28.9 \%$ & \\
\hline
\end{tabular}

\section{TABLE 6: Diabetic patients' overall knowledge regarding diabetic foot and their practice level.}

P: Pearson $X^{2}$ test. ${ }^{*} p<0.05$ (significant).

\section{Discussion}

The current study aimed to assess knowledge level of diabetic patients in Aseer region regarding diabetic foot and its care. Also, to identify their attitude towards diabetic foot care and their daily life practice regarding their foot care. Diabetic foot is one of the main complications of DM which diagnosed among nearly half of diabetic patients and causing about $80 \%$ of lower limb amputation [16,17]. Diabetic foot includes some type of neuropathy and angiopathy affecting mainly the foot ending with tissue damage, infection, and ulceration [9]. Poor diabetic control, long duration of uncontrolled diabetes, peripheral vasculopathy, older age, and poor awareness regarding diabetes generally and foot care particularly are the most known risk factors for diabetic foot [18].

In Saudi Arabia, diabetic foot ulcer is the leading cause of lower limb amputation, reference to the last few years, it caused lower limb amputation for $49.6 \%$ of cases [19] and it is predictable that this rate will show more increase next few years [20,21]. Diabetic foot in Saudi Arabia prevalent in 3.3\% of diabetic patients; 
with $2.1 \%$ suffered foot ulcer and $1.1 \%$ had amputation [11]. Diabetic foot complications are preventable relative to all other diabetic complications [22,23]. Awareness of patients about foot care is vital to avoid diabetic foot consequences, and amputation [24]. Foot complications including foot ulcers are more frequent among diabetic patients with poor awareness of their foot care [25].

The current study showed that more than two-thirds of the diabetic patients were knowledgeable regarding diabetic foot and its care. The highest awareness was for diabetic foot consequences (ulcers and gangrene) and they were aware of the effect of diabetes on foot blood supply and neuropathy associated with lack of sensation. Knowledge level was significantly higher among young aged patients which may be due to their worry of diabetes-related complications which may affect their future life, highly educated patients who can read, explore and had related information by their own selves, and those with a family history of DM. Literature review showed high variety in estimated diabetic patients' knowledge and awareness regarding diabetic foot and its care. This high variety of estimated awareness levels may be attributed to many factors including the method of awareness assessment, difference in samples characteristics and even the medical care strategies applied for diabetic patients in each country regarding doctor visits or ability to catch service and information through telephone. Solan YM et al. [26] found that 53.6\% of diabetic patients reported a good knowledge level regarding diabetic foot. Males were more complaint to foot drying by $65.2 \%$, while females are applying more attention to softening of skin by 72.3\%. In Tanzania, Chiwanga FS et al. [27] showed that the mean knowledge score for diabetic foot was 11.2 out of a total possible score of 23 (48.6\%). Low scores were reported among patients with low education $(8.3 \pm 6.1)$, diabetes duration of $<5$ years $(10.2$ \pm 6.7 ) and not receiving advice on foot care $(8.0 \pm 6.1)$. Among the 404 patients, $48 \%$ had received advice on foot care, and $27.5 \%$ had their feet examined by a doctor at least once since their initial diagnosis. Foot selfcare was significantly higher in patients who had received advice on foot care and in those whose feet had been examined by a doctor at least once. Locally, in Saudi Arabia, Algshanen MA [28] reported that 55.1\% of diabetic patients had high score for diabetic foot knowledge. About $69 \%$ had very low score $0-2$ out of 6 in the assessment of previous education of diabetic foot. More than half of the participants (56.5\%) had a score 6-10 out of 15 in the evaluation of practice with diabetic foot. Alhuqayl AA et al. [29] found that 53.3\%, of diabetic patients had good knowledge about diabetic foot while low knowledge represented $46.7 \%$ among participants. The significant determinants for god knowledge level included patients gender $(\mathrm{p}<0.001)$, education level $(p=0.001)$, DM type $(p=0.002)$, and suffering diabetic retinopathy $(p=0.009)$.

As for patients' attitude and practice, the current study showed that the vast majority of the study patients agreed that diabetics should check for any wounds on their feet daily, and that they should visit a doctor when there is any infection or wound in the feet. More than three-quarters of the patients think that diabetic patients should wear specialized shoes to avoid diabetic foot according to the doctor's instructions. Only 20.9\% agreed that Diabetics should not make periodic visits to the diabetes clinic for the purpose of examination and $16.5 \%$ believe that I can treat myself if I have diabetes without consulting a doctor. As for practice, more than $80 \%$ of the study patients wash their feet daily, but about half of them wear cotton socks. About half of the patients may walk barefoot which is unsafe due to the higher risk of trauma. Checking foot when had any problem was the most reported behaviour (68.6\%). Exact of $70.4 \%$ of the patients reported that they consult a physician when found any deformity (wound/ulcer) in their feet.

\section{Conclusions}

In conclusion, the current study results showed that nearly two out of each three diabetic patients were knowledgeable for diabetic foot and its care. High knowledge was associated with young age, high education and having family member with DM. Also, patients had a good attitude towards diabetic foot care and the effect of diabetes on foot health. Practice regarding patients' foot was satisfactory except for avoiding trauma leading causes including walking with bared feet and change shoes with damage only not periodically. Also, feet check frequency was not high among the patients. Diabetic patients need periodic health education programs and training for all disease-related complications including foot-related consequences.

\section{Additional Information \\ Disclosures}

Human subjects: Consent was obtained or waived by all participants in this study. Directorate Health Affairs-Aseer Region, Regional Committee for Research Ethics issued approval REC-02-09-2021. Dear, Dr.Ali Mohammed Al-Amri. I'm very pleased to inform you that your above-mentioned research proposal was discussed and approved. You are now granted to conduct your study given that no risk to participants and no disclosure of their identity. Animal subjects: All authors have confirmed that this study did not involve animal subjects or tissue. Conflicts of interest: In compliance with the ICMJE uniform disclosure form, all authors declare the following: Payment/services info: All authors have declared that no financial support was received from any organization for the submitted work. Financial relationships: All authors have declared that they have no financial relationships at present or within the previous three years with any organizations that might have an interest in the submitted work. Other relationships: All authors have declared that there are no other relationships or activities that could appear to have influenced the submitted work. 


\section{References}

1. Alam U, Asghar O, Azmi S, Malik RA: General aspects of diabetes mellitus. Handb Clin Neurol. 2014, 126:211-22. 10.1016/B978-0-444-53480-4.00015-1

2. Shamim M, Alhakbani MS, Alqahtani MS, Alharthi OS, Alhaqbani YJ: Knowledge, attitude, and practice regarding diabetic foot care among Saudi and non-Saudi diabetic patients in Alkharj. J Family Med Prim Care. 2021, 10:859-64. 10.4103/jfmpc.jfmpc_1681_20

3. Boulton AJ, Cavanagh PR, Rayman G, editors: The foot in diabetes. John Wiley \& Sons, 2006.

4. Singh N, Armstrong DG, Lipsky BA: Preventing foot ulcers in patients with diabetes . JAMA. 2005, 293:21728. 10.1001/jama.293.2.217

5. Vileikyte L: Diabetic foot ulcers: a quality of life issue . Diabetes Metab Res Rev. 2001, 17:246-9. 10.1002/dmrr.216

6. AlSadrah SA: Impaired quality of life and diabetic foot disease in Saudi patients with type 2 diabetes: a cross-sectional analysis. SAGE Open Med. 2019, 7:2050312119832092. 10.1177/2050312119832092

7. Wukich DK, Ahn J, Raspovic KM, La Fontaine J, Lavery LA: Improved quality of life after transtibial amputation in patients with diabetes-related foot complications. Int J Low Extrem Wounds. 2017, 16:11421. 10.1177/1534734617704083

8. Lauterbach S, Kostev K, Kohlmann T: Prevalence of diabetic foot syndrome and its risk factors in the UK . J Wound Care. 2010, 19:333-7. 10.12968/jowc.2010.19.8.77711

9. Lavery LA, Armstrong DG, Wunderlich RP, Mohler MJ, Wendel CS, Lipsky BA: Risk factors for foot infections in individuals with diabetes. Diabetes Care. 2006, 29:1288-93. 10.2337/dc05-2425

10. Hurley L, Kelly L, Garrow AP, et al.: A prospective study of risk factors for foot ulceration: the West of Ireland Diabetes Foot Study. QJM. 2013, 106:1103-10. 10.1093/qjmed/hct182

11. Al-Rubeaan K, Al Derwish M, Ouizi S, Youssef AM, Subhani SN, Ibrahim HM, Alamri BN: Diabetic foot complications and their risk factors from a large retrospective cohort study. PLoS One. 2015, 10:e0124446. 10.1371/journal.pone.0124446

12. Lim JZ, Ng NS, Thomas C: Prevention and treatment of diabetic foot ulcers . J R Soc Med. 2017, 110:104-9. 10.1177/0141076816688346

13. Ramirez-Perdomo C, Perdomo-Romero A, Rodríguez-Vélez M: Knowledge and practices for the prevention of the diabetic foot. Rev Gaucha Enferm. 2019, 40:e20180161. 10.1590/1983-1447.2019.20180161

14. LoGerfo FW, Coffman JD: Current concepts. Vascular and microvascular disease of the foot in diabetes. Implications for foot care. N Engl J Med. 1984, 311:1615-9. 10.1056/NEJM198412203112506

15. Pendsey S, Abbas ZG: The step-by-step program for reducing diabetic foot problems: a model for the developing world. Curr Diab Rep. 2007, 7:425-8. 10.1007/s11892-007-0071-x

16. Gupta SK, Singh SK: Diabetic foot. In: Diabetes: an old disease, a new insight . Ahmad SI (ed): Springer, New York, NY; 2013. 123-38. 10.1007/978-1-4614-5441-0 12

17. Siersma V, Thorsen H, Holstein PE, et al.: Importance of factors determining the low health-related quality of life in people presenting with a diabetic foot ulcer: the Eurodiale study. Diabet Med. 2013, 30:1382-7. 10.1111/dme.12254

18. Al-Wahbi AM: The diabetic foot in the Arab World . Saudi Med J. 2006, 27:147-53.

19. Al Zahrani HA, Ghandora NM, Merdad HT: Limb amputation in western Saudi Arabia . Asian J Surg. 1992, 15:119-22.

20. Tashkandi WA, Badri MM, Badawood SM, Ghandoura NA, Kensarah AM, Alzahrani HA: Lower limb amputation among diabetics in three major hospitals in Jeddah, Saudi Arabia. JKAU Med Sci. 2011, 18:23-35.

21. Badri MM, Tashkandi WA, Nawawi A, Alzahrani HA: Extremities amputations in King Abdulaziz University Hospital (2005-2009). JKAU Med Sci. 2011, 18:13-25. 10.4197/Med.18-2.2

22. The diabetic foot. Position statement. International Diabetes Federation . (2014). http://www.idf.org/position-statement-diabetic-foot.

23. Chandalia HB, Singh D, Kapoor V, Chandalia SH, Lamba PS: Footwear and foot care knowledge as risk factors for foot problems in Indian diabetics. Int J Diabetes Dev Ctries. 2008, 28:109-13. 10.4103/09733930.45269

24. Wu SC, Driver VR, Wrobel JS, Armstrong DG: Foot ulcers in the diabetic patient, prevention and treatment. Vasc Health Risk Manag. 2007, 3:65-76.

25. Chellan G, Srikumar S, Varma AK, et al.: Foot care practice - the key to prevent diabetic foot ulcers in India . Foot. 2012, 22:298-302. 10.1016/j.foot.2012.08.007

26. Solan YM, Kheir HM, Mahfouz MS, et al.: Diabetic foot care: knowledge and practice . J Endocrinol Metab. 2016, 6:172-7. 10.14740/jem388e

27. Chiwanga FS, Njelekela MA: Diabetic foot: prevalence, knowledge, and foot self-care practices among diabetic patients in Dar es Salaam, Tanzania - a cross-sectional study. J Foot Ankle Res. 2015, 8:20. 10.1186/s13047-015-0080-y

28. Algshanen MA, Almuhanna MF, Almuhanna AM, et al.: Diabetic foot awareness among diabetic patients in Saudi Arabia. Egyptian J Hosp Med. 2017, 68:1289-90. 10.12816/0039063

29. Alhuqayl AA, Alaskar MS, Alsahli FM, Alaqil SA: Awareness of foot care among diabetic patients. IJMDC. 2019, 3:154-8. 10.24911/IJMDC.51-1540846403 